\title{
Epidermoid Cyst versus Basal Cell Carcinoma by Dermoscopy
}

\author{
Alin Laurentiu Tatu ${ }^{1 *}$, Elena Lacramioara Lisa ${ }^{2}$, Claudia Simona Stefan ${ }^{2}$
}

${ }^{1}$ Faculty of Medicine, Pharmacy-Dermatology department, University Dunarea de Jos, Galati, Romania, Private Practice, Galati, Romania

${ }^{2}$ Faculty of Medicine, Pharmacy-Dermatology department, University Dunarea de Jos, Galati, Romania

*Corresponding author: Alin Laurentiu Tatu, AL.I.Cuza Street No 39, Galati, Postal code-800101, Romania, Tel: 00-40-728267435; Fax: 00-40-236-415705; E-mail: dralin_tatu@yahoo.com

\begin{abstract}
A 70 years old woman presented with a two years history of small white nodules on her eyelids. The small and pigmented lesion had slowly grown since three months ago. She had a previous history of basal cell carcinoma on the chest 7 years ago. Dermoscopy showed telangiectasias and come dos but lack of arborising vessels and blue ovoid nests. A presumptive diagnosis of Epidermoid Cysts and facial come dos was made. Dermoscopy is a simple and noninvasive method to diagnose different skin conditions.
\end{abstract}

Received date: October 22, 2016

Accepted date: : March 23, 2017

Published date: : March 23, 2017

Citation: Tatu, A.L., et al. Epidermoid Cyst versus Basal Cell Carcinoma by Dermoscopy. (2017) Invest Dermatol Venereol Res 3(1): 103- 104.

Keywords: Epidermoid cyst; Basal cell carcinoma; Dermoscopy

DOI: $10.15436 / 2381-0858.17 .1182$

\section{Case Report}

A 70 years old woman presented with a two years history of small white nodules on her eyelids. The small and pigmented lesion had slowly grown since three months ago. She had a previous history of basal cell carcinoma on the chest 7 years ago. On examination there were dome-shaped, flesh colored nodules around the eyelids, the smaller lesion with a central brown-black pigmentation (Figure.1), the big nodule had also a small central black spot and an isolated one. Dermoscopy revealed the central brown circular comedo (Figure 2) situated on a whitish-yellow circular background with some telangiectasias on it due to pressure and skin distension. By dermoscopy the central small brown comedo on the big nodule was revealed (Figure 3) and also the isolated comedo (Figure 4). A presumptive diagnosis of Epidermoid Cysts and facial come dos was made. The patient was insured about the benign nature of the condition and was explained that they should be removed if the appearance bothers or become painful, ruptured or infected.

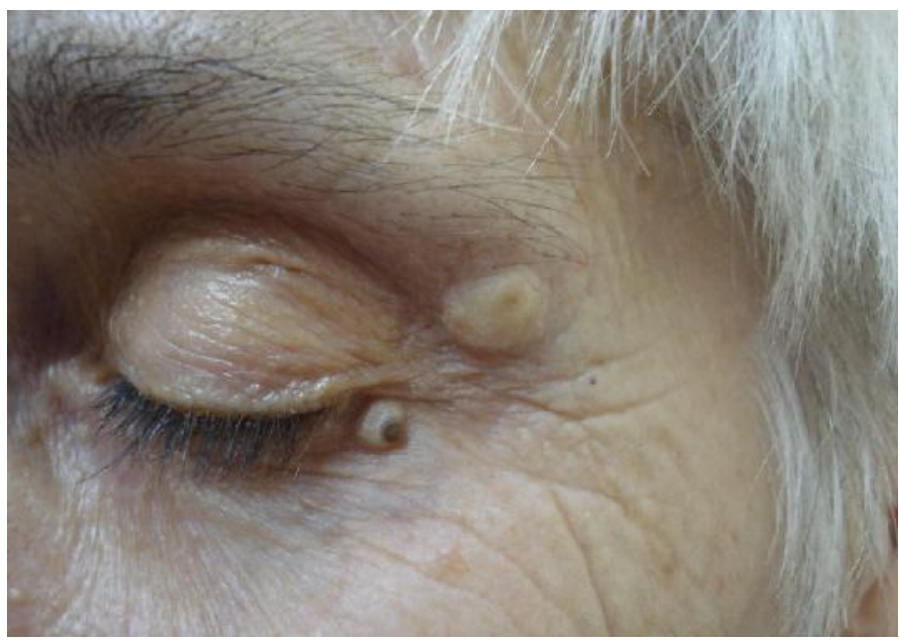

Figure 1: Flesh-colored nodules with central pigmentation around the eyelids. 


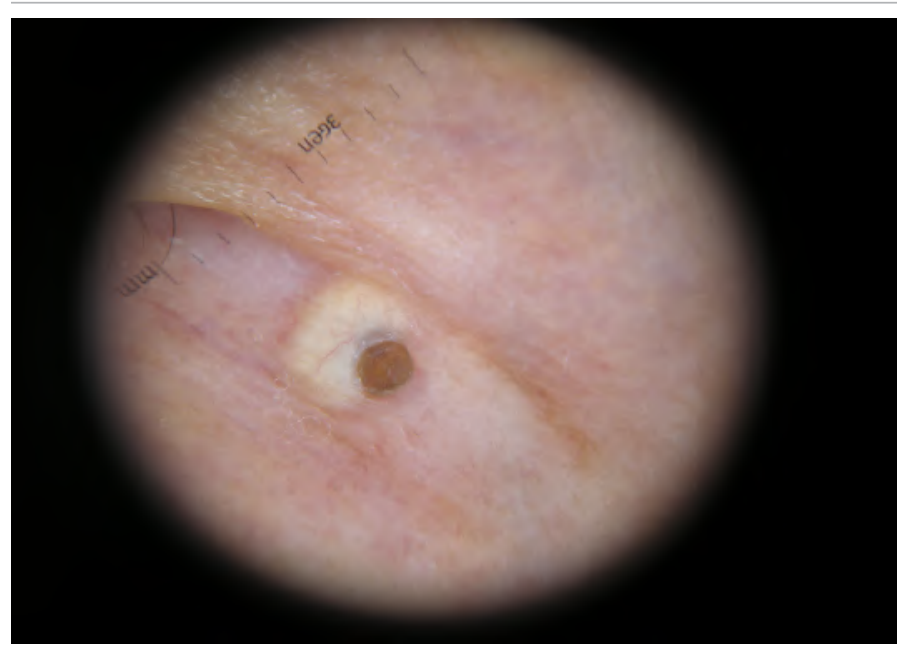

Figure 2: Central brown circular comedo on a whitish-yellow circular background, telangiectasias -Dermoscopy.

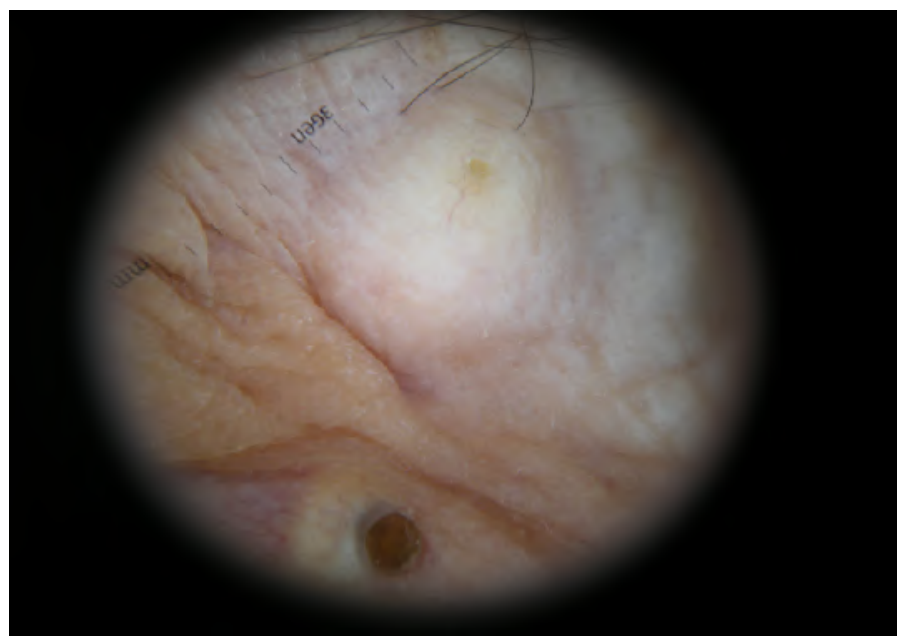

Figure 3: Central small brown comedo on the big nodule, telangiectasias-Dermoscopy.

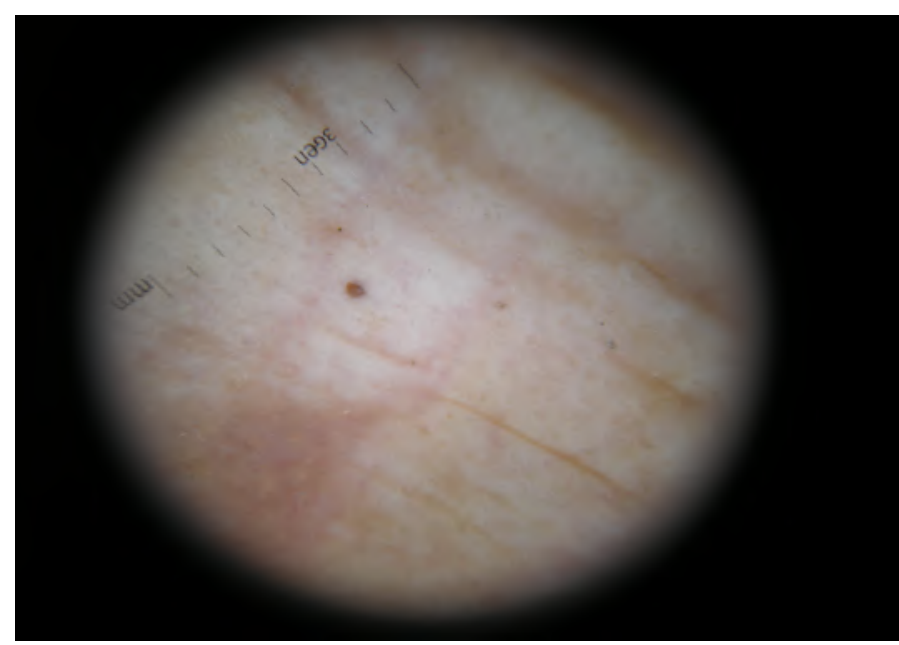

Figure 4: Isolated comedo-Dermoscopy.

\section{Discussion}

Patients with previous history of cutaneous cancer are very scared about new or growing lesions on the skin. Sometime the clinical examination gives the diagnostic clue but sometime dermoscopy improve the clinical impression. From clinical point of view the epidermoid cyst had sometime vessels due the distension of the skin and also a slowly growing time as Basal Cell Carcinoma (BCC). The soft tissue ultrasound exam often gives the diagnostic clue but sometime dermoscopy improves the diagnostic. Dermoscopy in this case revealed vessels, but the diagnostic clue was the presence of the comedones and the lack of blue large ovoid nests and of arborising vessels-clues for BCC.

\section{Conclusions}

Dermoscopy is a simple and noninvasive method to diagnose different skin conditions. Dermoscopic features of Epidermal Cyst are the comedos (sometime too small to be recognized by the naked eye) and the absence of other criteria for $\mathrm{BCC}$-arborising vessels and large ovoid nests ${ }^{[1,2]}$.

\section{References}

1. Longo, C., Lallas, A., Kyrgidis, A., et al. Classifying distinct basal cell carcinoma subtype by means of dermatoscopy and reflectance confocal microscopy. (2014) J Am Acad Dermatol 71(4): 716-724.

Pubmed I Crossref I Others

2. Bombonato, C., Piana, S., Moscarella, E., et al. Pigmented eccrine poroma: dermoscopic and confocal features. (2016) Dermatol Pract Concept 6(3): 59-62.

Pubmed

\section{Online ISSN: 2381-0858}

Journal Title: Investigative Dermatology and Venereology Research Journal Short Name: Invest Dermatol Venereol Res
Website: www.ommegaonline.org 